\title{
Assessment of the Performance and Defect Investigation of PV Modules after Accelerated Ageing Tests
}

\author{
J.A. Tsanakas ${ }^{1}$, M. Karoglou ${ }^{2}$, E.T. Delegou ${ }^{2}$, P.N. Botsaris ${ }^{1}$, A. Bakolas ${ }^{2}$, A. Moropoulou ${ }^{2}$ \\ ${ }^{1}$ Democritus University of Thrace, School of Engineering \\ Department of Production Engineering and Management \\ Faculty of Materials, Processes and Engineering \\ Central University Campus, Building I - 12 Vas. Sofias str, 67100 Xanthi (Greece) \\ Phone/Fax number: +30 2541079878, e-mail: itsanaka@ee.duth.gr, panmpots@pme.duth.gr \\ ${ }^{2}$ National Technical University of Athens, School of Chemical Engineering \\ Department of Materials Science and Engineering \\ Zografou University Campus - 9 Iroon Polytechneiou str., 15780 Zografou, Athens (Greece) \\ Phone/Fax number: +30 2107723276 / 2107723215
}

e-mail: margo@central.ntua.gr, edelegou@central.ntua.gr, abakolas@central.ntua.gr, amoropul@central.ntua.gr

\begin{abstract}
Photovoltaic (PV) modules' degradation behaviour, together with outdoor field condition and fault diagnostics, consist valuable data in evaluating efficiency and establishing long-term reliability of a PV system. However, since PV modules commonly come with 25 (even over) years of warranty, testing modules in field for that long period is not feasible. Thus, due to time constraints, many accelerated aging tests have been recently introduced for testing reliability and durability of PV modules. Scope of the presented study is the assessment of the performance degradation and fault (defect) propagation mechanisms with regard to three monocrystalline silicon (mc-Si) PV modules, through a specific thermal cycle accelerated ageing test. The parameters that were experimentally evaluated towards the accelerated ageing process of this study, were: i) the thermal signature evolution and/or propagation of any diagnosed defects, especially in two modules, by means of infrared (IR) thermographic measurements, ii) the overall performance degradation of each module, by means of electrical I-V measurements, together with iii) specific morphological characteristics, by means microscopy imaging. The intended study gave useful and promising results in assessing the effect of the applied thermal cycles upon the modules' thermal behaviour, electrical efficiency and morphology.
\end{abstract}

\section{Key words}

PV modules degradation, defect propagation, accelerated ageing, infrared thermography, I-V measurements.

\section{Introduction}

PV modules are probably the most important component of any PV system. In fact, payback time and life cycle costs are mainly determined by the initial power output, power degradation, and the lifetime of the module. Therefore, guaranteed quality and operation reliability comprise fundamental requirements that provide the basis for the profitability and security of such investments [1].
Of course, when thinking about long-term reliability of a PV module, the need for certified, zero-defect manufacturing and better understanding of degradation mechanisms emerges as sine quo non. Today, the majority of manufactured PV modules are warranted for a 25-year life. These modules are typically qualified to specific norms, such as IEC 61215 or IEC 61646, which are supposed to identify design, materials, and process flaws that are likely to lead to premature failure (infant mortality) [2]. Furthermore, defective cells are ideally identified and rejected during the early stages of a module's manufacturing process, using e.g. ultrasonic methods [3], thermal flux thermography [4-7] or electroluminescence (EL) imaging [8,9]. However, the qualification tests are not designed to address wear-out mechanisms, occurring in real field conditions, which may limit module lifetime. Understanding these mechanisms is of utmost importance from several perspectives [10]:

- Optimum and realistic warranty periods, adequate reliability tests and module design improvements for future manufacturers.

- More precise estimations of PV modules' lifetimes and, thus, more accurate models of life cycle costs for future investors.

- Scheduling of appropriate maintenance strategies for future plant operators.

- Decrease the PV electricity costs while increasing reliability of the PV module.

The study of degradation and failure mechanisms in PV modules is often based on accelerated ageing tests (AAT), where failure effects are reproduced and quantified [1117]. If it is assumed that characterization and monitoring methods, such as I-V measurements and infrared 
thermography (IRT), are already established means of defect detection and diagnosis, the strong need for prognosis and long-term reliability gives the impetus of further research.

Main scope of this study is to assess the potential of an accelerated ageing test, in the form of thermal cycling, and field measurements, in the form of infrared thermography and I-V measurements, in providing thorough and reliable knowledge upon the performance degradation and (possible) defect propagation of specific mc-Si PV modules.

\section{Experimental set-up}

The testing objects of this study were three mc-Si PV modules, named as $P V-1, P V-2$ and $P V-3 . P V-1$ consists of $33 \mathrm{mc}-\mathrm{Si}$ solar cells (Figure 1) and according to its specifications (at standard test conditions, STC), features a $P_{\text {max }}$ of $6 \mathrm{~W}_{\mathrm{P}}$ (for which it is $I_{m p p}=0.39 \mathrm{~A}$ and $V_{m p p}=15 \mathrm{~V}$ ), short-circuit current $I_{S C}=0.42 \mathrm{~A}$ and open-circuit voltage $V_{O C}=19.5 \mathrm{~V} . P V-2$ and $P V-3$ consist of $36 \mathrm{mc}-\mathrm{Si}$ solar cells (Figure 2) and feature (at STC) a $P_{\max }=5 \mathrm{~W}_{\mathrm{P}}$ (for which it is $I_{m p p}=0.285 \mathrm{~A}$ and $\left.V_{m p p}=17.82\right), I_{S C}=0.315 \mathrm{~A}$ and $V_{O C}=21.96 \mathrm{~V}$.

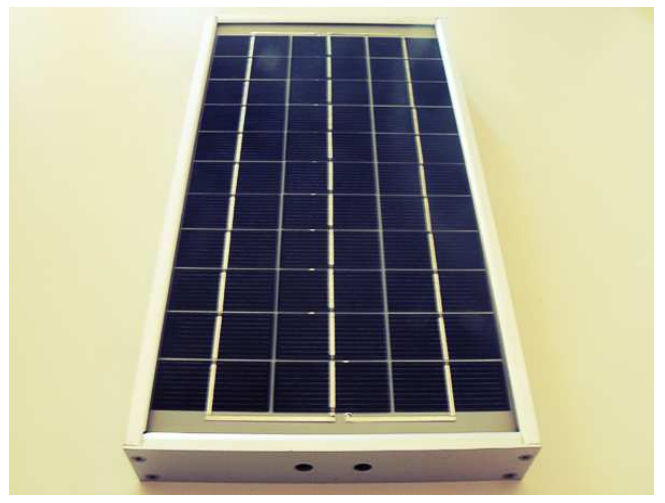

Fig. 1. The $P V-1$ module.

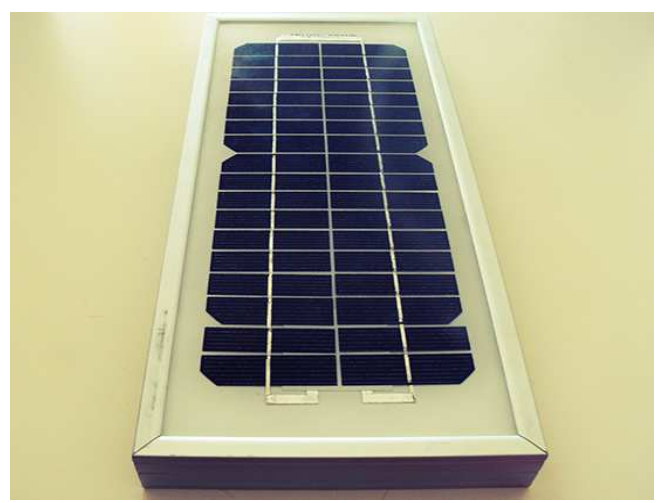

Fig. 2. The $P V-2$ (and $P V-3$ ) module.

The thermal cycling test was performed at an Angelatoni Industrie GTS600 accelerating ageing test chamber (Figure 3), including a total number of 106 thermal cycles (Figure 4), from $-15^{\circ} \mathrm{C}$, to $+70^{\circ} \mathrm{C}$, with ambient (starting) temperature of $25^{\circ} \mathrm{C}$, and a temperature change ratio of $0.8^{\circ} \mathrm{C} / \mathrm{min}$., resulting to a total duration of about $4.5 \mathrm{hrs}$ per cycle.

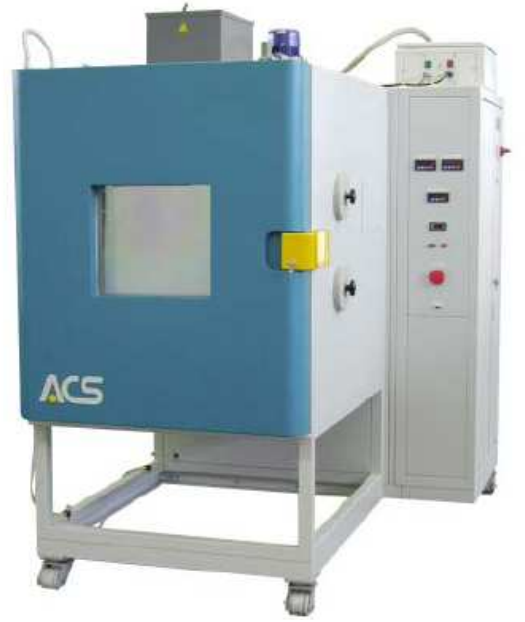

Fig. 3. The Angelatoni GTS600 test chamber.

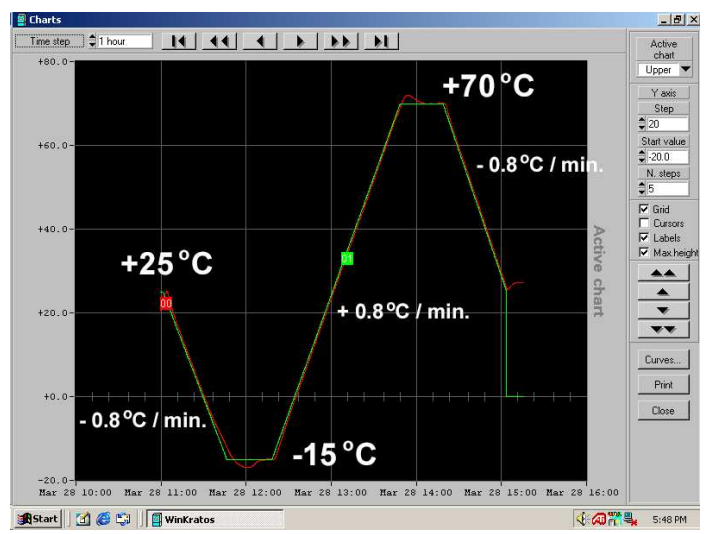

Fig. 4. The thermal cycling scenario of the study.

Each module of this study underwent non-destructive IR thermographic, optical (microscopic) and I-V measurements, before ( 0 cycles $)$, in the middle (53 cycles) and at the end (106 cycles) of the ageing process.

IR measurements were performed by two portable thermal imagers; an Impac IVN780-P (Figure 5) and a FLIR B200 (Figure 6). IVN 780- $P$ features a $320 \times 240$ uncooled focal plane array (UFPA) microbolometer detector with a spectral range of 8 to $14 \mu \mathrm{m}$, temperature range of -40 to $+1000{ }^{\circ} \mathrm{C}$ with temperature resolution of $0.1{ }^{\circ} \mathrm{C}$, image resolution of $320 \times 240$ pixels and instantaneous field of view (IFOV) of $1.5 \mathrm{mrad}$. On the other hand, FLIR B200 features a $200 \times 150$ UFPA microbolometer detector with a spectral range of 7.5 to $13 \mu \mathrm{m}$, temperature range of -20 to $+120{ }^{\circ} \mathrm{C}$ with temperature resolution of $0.08{ }^{\circ} \mathrm{C}$, image resolution of $200 \times 150$ pixels and IFOV of $2.18 \mathrm{mrad}$. All $\mathrm{I}-\mathrm{V}$ measurements were performed with the use of a Range RE69 41/2 DMM conventional multimeter, providing the magnitudes of $\mathrm{I}_{\mathrm{SC}}$ (short-circuit current) and $\mathrm{V}_{\mathrm{OC}}$ (open-circuit voltage). The specific model has a $0.1 \%$ basic accuracy with a $2 \mathrm{~mA}-10 \mathrm{~A}$ DC current range and a $200 \mathrm{mV}-1000 \mathrm{~V}$ DC voltage range. The modules were short-circuited and open-circuited in the field, under illumination (clear-sky conditions), with a fixed inclination of $30^{\circ}$. Last but not least, the optical measurements were performed by an i-Scope Moritex fiber optic microscope (FOM) and a specialized photographic lens Nikkor AF Micro $60 \mathrm{~mm}$. 


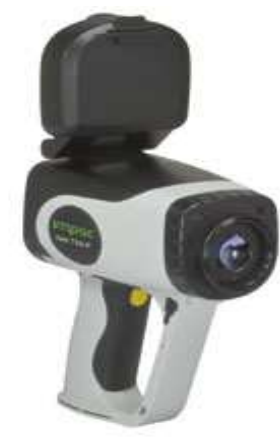

Fig. 5. The Impac IVN780-P portable thermal imager.

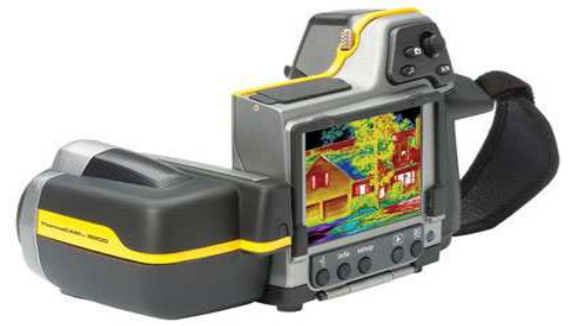

Fig. 6. The FLIR B200 portable thermal imager.

During each measurement ( 0 thermal cycles, 53 thermal cycles and 106 thermal cycles), the values of cell/module surface temperature $T_{c}$ (only before I-V measurements), ambient temperature $T_{a}$, relative humidity $R H$, wind velocity $V_{f}$ and solar irradiance $G_{T}$, were taken into account (Table I) for three different reasons: for the initial set-up of the thermal imagers, ii) for the estimation of the expected (theoretical) cell temperature (during IR thermographic measurements) and iii) for the estimation of the maximum power output of each PV module (during the I-V measurements). It should be mentioned that, before each IR measurement, both thermal imagers were initially calibrated using ambient and reflected temperature compensation and were set to emissivity $\varepsilon=0.85$, equal to the emissivity factor of the modules' front cover material (glass).
Table I. The environmental conditions of each measurement.

\begin{tabular}{|r|ccc|}
\hline Measurement & $\mathbf{0}$ cycles & $\mathbf{5 3}$ cycles & $\mathbf{1 0 6}$ cycles \\
$\left.\mathrm{T}_{\mathbf{c}} \boldsymbol{(}^{\circ} \mathrm{C}\right)$ & 27 & 29 & 28 \\
during I-V measurement & 23 & 24 & 26 \\
$\mathrm{~T}_{\mathbf{1}}\left({ }^{\circ} \mathrm{C}\right)$ & 23 & 30 & 30 \\
$\mathbf{R H}(\%)$ & 35 & 6 & 4,8 \\
$\mathbf{V}_{\mathrm{f}}(\mathbf{m} / \mathrm{s})$ & 5,3 & 945 & 978 \\
$\mathbf{G}_{\mathrm{T}}\left(\mathbf{W} / \mathbf{m}^{2}\right)$ & 955 & & \\
\hline
\end{tabular}

\section{Results and Discussion}

\section{A. IR Thermography measurements}

Figure 7 presents the resultant thermal images from the IR measurements of IVN780-P, that show the evolution of $P V-1, P V-2$ and $P V-3$ thermal signatures over the effect of different ageing process stages: 0 thermal cycles (initial state) 53 thermal cycles (half-aged) and 106 thermal cycles (fully-aged). Similar results were obtained by the $B 200$ thermal imager. In order to achieve significant thermal response and variations over any possible defect, all modules underwent IR measurements after 15 to 30 minutes of field exposure, under short-circuit conditions. The acquired thermal images from the inspected PV modules were analyzed in order to generate a simple and fast correlation between the expected cell temperatures $\left(T_{c, \text { exp }}\right)$ of each module and the measured cell temperatures $\left(T_{c, m}\right)$, obtained from these field thermographic inspections. In practice, a $\Delta T>5{ }^{\circ} \mathrm{C}$ between $T_{c, \exp }$ and $T_{c, m}$ witnesses a potential defect (hot spot) [1]. According to Skoplaki et al. [18], the expected operating cell temperature, can be fairly estimated by the following semi-empirical equation:

$$
T_{c, \exp }=T_{a}+\left(\frac{0.32}{8.91+2 \cdot V_{f}}\right) \cdot G_{T}
$$

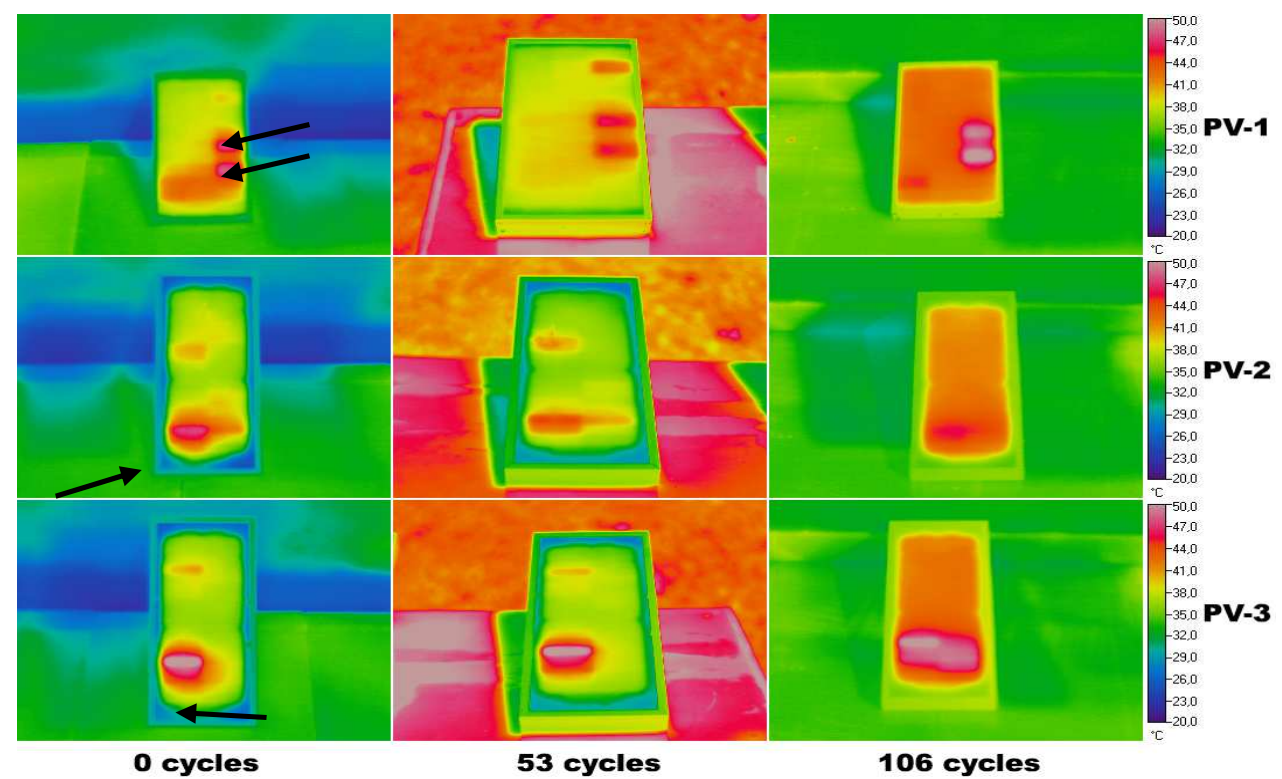

Fig. 7. The resultant thermal images for $P V-1, P V-2, P V-3$, during the IR measurements of 0,53 and 106 thermal cycles. 
Beginning with the thermal image analysis of $P V-1$, the attention is focused on two "suspicious" cells (as indicated by the black arrows in Figure 7), which were measured with an average cell temperature $T_{c, m}=47.5^{\circ} \mathrm{C}$. At the same time, an apparently "healthy" cell in $P V-1$, presents a $T_{c, m}=38^{\circ} \mathrm{C}$. Applying eq. (1), for the environmental parameters of this measurement $(0$ thermal cycles), given in Table $\mathrm{I}$, the expected cell temperature is estimated to $T_{c, \exp }=38.7^{\circ} \mathrm{C}$. Thus, the "healthy" cells, here, are operating to a temperature very close (by $1.8 \%$ ) to the theoretical $T_{c, \text { exp }}$, in contrast to two cells, diagnosed as defective, as they present an abnormal operating temperature, higher than the normal one by a $\Delta T=8.8^{\circ} \mathrm{C}$. Similarly, a significant $\Delta T$ was observed to the operating temperatures of the defective cells, after both 53 and 106 thermal cycles, without - however - any significant change to their thermal signature. In particular, after 53 thermal cycles, a $T_{c, m}=38.7^{\circ} \mathrm{C}$ was measured for the normally operating cells, almost equal to the theoretically estimated (for this measurement conditions) $T_{\text {cexp }}=38.5^{\circ} \mathrm{C}$, while the two defective cells presented an abnormally high operating temperature of $T_{c, m}=45.6^{\circ} \mathrm{C}$, corresponding to a $\Delta T=7.1{ }^{\circ} \mathrm{C}$, indicative of certain fault. Moreover, after 106 thermal cycles, with a theoretically estimated $T_{c, \text { exp }}=42.9^{\circ} \mathrm{C}$, a small declination of $2.3 \%$ and a $\Delta T=6.1^{\circ} \mathrm{C}$ were measured for the operating temperature of the "healthy" $\left(T_{c, m}=41.9^{\circ} \mathrm{C}\right)$ and the defective $\left(T_{c, m}=49^{\circ} \mathrm{C}\right)$ cells of $P V-1$, respectively.

Continuing, in the same way, with the analysis of the thermal images of $P V-2$, at the initial state of the module (before ageing, 0 thermal cycles), the attention was focused on the presence of a "suspicious" area, indicated by the black arrow in Figure 7 , which was related to a $\Delta T=7.4^{\circ} \mathrm{C}$ between the expected and the measured operating temperature. For the same area, after 53 and 106 thermal cycles, it was measured, within the thermal images, a $\Delta T=5.3^{\circ} \mathrm{C}$ and a $\Delta T=3.7^{\circ} \mathrm{C}$, respectively, which do not correspond to a clear indication of defect. Although the specific abnormality in the temperature profile of this area is probably related to the presence of the junction box - at the backside cover of the module further investigation has been made during the analysis of theI-V measurements (see next subsection).

Finally, in the thermal image analysis of $P V-3$ module, a "suspicious" cell, with an abnormal temperature profile, has been detected at the initial state, as (similarly to the previous ones) indicated in Figure 7 . For the specific cell and for the three stages of ageing $(0,53$ and 106 thermal cycles) the related thermal images revealed a significant $\Delta T$ of $21.1^{\circ} \mathrm{C}, 15.5^{\circ} \mathrm{C}$ and $8.9^{\circ} \mathrm{C}$, respectively. Moreover, in contrast to the defective cases of $P V-1$ and $P V-2$, here the defect appears to change and propagate to the adjacent cells after the conclusion of the 106 thermal cycles, resulting to a defective area of a larger extent, compared to the initial state. In particular, while the defective area of $P V-3$, at the initial state, includes one cell, the effect of thermal cycle ageing has apparently led to an extension of this area to a total number of four cells and, subsequently, to further power degradation, as it will be shown in the next subsection.
It should be clarified that the noticed decrease of the $\Delta T$ value, during the ageing process, in all three cases of PV modules, does not imply any restriction of the defects' severity and their impact to the modules' power degradation. It can, though, be explained as a result of the expansion of the dissipated heat to the defective areas and its allocation to each whole module.

\section{B. Electrical I-V measurements}

In this study, the electrical efficiency $n(\%)$ and efficiency (power) degradation $\Delta n(\%)$, for each module and each ageing stage, are given in Table II, as they were estimated using specific I-V measurements and according to the following steps:

1. Estimation of the electrical efficiency $n_{0}$ of each module, at STC, according to the provided electrical and technical specifications, by applying eq. (2) [19]. The subscript " 0 " here, refers to STC. $F F$ and $A$ refer to the fill factor and total cell matrix area, respectively.

$$
n_{0}=\frac{P_{\max -0}}{A \cdot G_{T-0}}=\frac{V_{O C-0} \cdot I_{S C-0} \cdot F F_{0}}{A \cdot 1000}
$$

2. Estimation of the theoretical (expected) values of $I_{S C}$ and $V_{O C}$, for each module, reduced to the environmental conditions of each I-V measurement (0, 53 and 106 thermal cycles), according to eq. (3) and (4) [19], respectively, and using the values of $G_{T}$ and $T_{c}$, given by Table I. At STC, it is $G_{T-0}=1000 \mathrm{~W} / \mathrm{m}^{2}$ and $T_{c-0}=25^{\circ} \mathrm{C}$.

$$
\begin{gathered}
I_{S C}=\frac{G_{T}}{G_{T-0}} \cdot I_{S C-0} \\
V_{O C}=V_{O C-0}+c \cdot\left(T_{c}-T_{c-0}\right)
\end{gathered}
$$

3. Estimation of the theoretical (expected) $F F$ of each module, reduced to the environmental conditions of each measurement, according to eq. (5) [20], using the value of $V_{O C}$ as estimated by eq. (4).

$$
F F=\frac{V_{O C}-\ln \left(V_{O C}+0.72\right)}{V_{O C}+1}
$$

4. Estimation of the theoretical (expected) $P_{\max }$ and $n$ of each module, reduced to the environmental conditions of each measurement, according to eq. (6) and eq. (7) respectively, using the values of $I_{S C}, V_{O C}$ and $F F$, from eq. (3), (4) and (5).

$$
\begin{gathered}
P_{\max }=V_{O C} \cdot I_{S C} \cdot F F \\
n=\frac{P_{\max }}{A \cdot G_{T}}
\end{gathered}
$$


5. Measurement of the actual values $I_{S C}$ and $V_{O C}$, of each module, for 0,53 and 106 thermal cycles and estimation of the respective actual values of $F F, P_{\max }$ and $n$, according to eq. (5), (6) and (7).
6. Comparison between the theoretical (expected) and actual values of electrical efficiency $n$ of each module, for 0,53 and 106 thermal cycles and estimation of the respective overall electrical efficiency degradation $\Delta n$.

Table II. Theoretical (expected) and measured (actual) values of basic electrical parameters and efficiency degradation of $P V-1, P V-2$ and $P V-3$, for the I-V measurements at the three stages of the ageing study; 0,53 and 106 thermal cycles.

\begin{tabular}{|c|c|c|c|c|c|c|c|}
\hline \multirow{2}{*}{ Parameter } & \multirow{2}{*}{$\begin{array}{l}\text { Value } \\
\text { @ STC }\end{array}$} & \multicolumn{3}{|c|}{ Theoretical (expected) values } & \multicolumn{3}{|c|}{ Measured (actual) values } \\
\hline & & 0 & 53 & 106 & 0 & 53 & 106 \\
\hline$P_{\max }(\mathbf{W})$ & 6.00 & 5.657 & 5.545 & 5.766 & 5.228 & 4.664 & 4.713 \\
\hline$I_{\max }(\mathrm{A})$ & 0.39 & & & & & & \\
\hline$I_{s c}(\mathbf{A})$ & 0.42 & 0.401 & 0.397 & 0.411 & 0.374 & 0.342 & 0.350 \\
\hline$V_{\max }(\mathrm{V})$ & 15.00 & & & & & & \\
\hline$V_{o c}(\mathbf{V})$ & 19.50 & 19.346 & 19.192 & 19.269 & 19.200 & 18.800 & 18.600 \\
\hline$F F(\%)$ & 73 & 72.9 & 72.8 & 72.8 & 72.8 & 72.5 & 72.4 \\
\hline$C\left(\mathrm{~V} /{ }^{\circ} \mathrm{C}\right)$ & -0.077 & & & & & & \\
\hline$A\left(\mathrm{~m}^{2}\right)$ & 0.0445 & & & & & & \\
\hline$n(\%)$ & 13.49 & 13.3 & 13.2 & $\begin{array}{ll}3.3 \\
\cdots\end{array}$ & 12.3 & 11.1 & 10.8 \\
\hline$\Delta n(\%)$ & & & & & -7.6 & -15.9 & -18.3 \\
\hline$P_{\max }(\mathrm{W})$ & 5.00 & 4.716 & 4.626 & 4.809 & 4.625 & 4.426 & 4.548 \\
\hline$I_{\max }(\mathrm{A})$ & 0.285 & & & & & & \\
\hline$I_{s c}(\mathbf{A})$ & 0.315 & 0.301 & 0.298 & 0.308 & 0.295 & 0.290 & 0.298 \\
\hline$V_{\max }(\mathrm{V})$ & 17.82 & & & & & & \\
\hline$V_{o c}(\mathrm{~V})$ & 21.96 & 21.798 & 21.636 & 21.717 & 21.800 & 21.300 & 21.300 \\
\hline$F F(\%)$ & 72 & 71.9 & 71.8 & 71.9 & 71.9 & 71.7 & 71.7 \\
\hline$c\left(\mathrm{~V} /{ }^{\circ} \mathrm{C}\right)$ & -0.081 & & & & & & \\
\hline$A\left(\mathbf{m}^{2}\right)$ & 0.0397 & & & & & & \\
\hline$n(\%)$ & 12.60 & 12.4 & 12.3 & 12.4 & 12.2 & 11.8 & 11.7 \\
\hline$\Delta n(\%)$ & 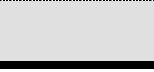 & & & & -1.9 & -4.3 & -5.4 \\
\hline$P_{\max }(\mathbf{W})$ & 5.00 & 4.716 & 4.626 & 4.809 & 4.460 & 4.106 & 4.127 \\
\hline$I_{\max }(\mathrm{A})$ & 0.285 & & & & & & \\
\hline$I_{s c}(\mathrm{~A})$ & 0.315 & 0.301 & 0.298 & 0.308 & 0.286 & 0.272 & 0.278 \\
\hline$V_{\text {max }}(V)$ & 17.82 & & & & & & \\
\hline$V_{o c}(\mathbf{V})$ & 21.96 & 21.798 & 21.636 & 21.717 & 21.700 & 21.100 & 20.800 \\
\hline$F F(\%)$ & 72 & 71.9 & 71.8 & 71.9 & 71.9 & 71.5 & 71.4 \\
\hline$c\left(\mathrm{~V} /{ }^{\circ} \mathrm{C}\right)$ & -0.081 & & & & & & \\
\hline$A\left(\mathbf{m}^{2}\right)$ & 0.0397 & & & & & & \\
\hline$n(\%)$ & 12.60 & 12.4 & 12.3 & 12.4 & 11.8 & 10.9 & 10.6 \\
\hline$\Delta n(\%)$ & & & & & -5.4 & -11.2 & -14.2 \\
\hline
\end{tabular}

The results of the electrical measurements of this study, concluded and presented in Table I, indicate an apparent overall power (and, thus, efficiency) degradation, by $18.3 \%, 5.4 \%$ and $14.2 \%$, as a result of both the applied thermal cycles, through the ageing process, and the existent defects' impact to $P V-1$ and $P V-3$. Although the three modules underwent thermal cycling under different initial conditions of defects and efficiency, their 
measured electrical efficiency degradation presents the following common characteristics:

- The efficiency degradation rate of all modules appears to be higher at the first part of the ageing process (from 0 to 53 thermal cycles) than those at the second part (from 53 to 106 thermal cycles).

- The efficiency degradation at the end of the ageing process (after 106 thermal cycles) is found to be about 2.5 higher than the initial one, before ageing.

\section{Morphological observations}

Figures 8-10 present the resultant optical microscopy images of defective cells in $P V-1$ and $P V-3$, as diagnosed by the IR measurements, after the completion of the ageing process (106 thermal cycles). As Figure 8 suggestively shows, the specific defective cell in $P V-1$ presents partial discoloration (indicated by the yellow arrow), which is characteristic of a degraded ethylene vinyl acetate (EVA) encapsulant film. Similar parts of defective cells were noticed in Figure 9, due to either electrical mismatches (distorted busbars, $1^{\text {st }}$ arrow) degraded EVA film (brown discolorations, $2^{\text {nd }}$ arrow) or possibly degraded anti-reflection coating of the cells (cyan discolorations, $3^{\text {rd }}$ arrow). With regard to Figure 10 , the defective parts of $P V-3$ were found with specific cyan discolorations, possibly related to degraded antireflection coating, as in the $3^{\text {rd }}$ case of Figure 9.

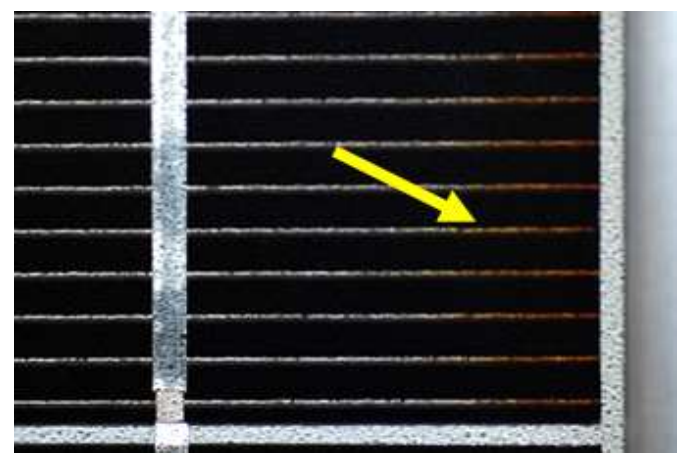

Fig. 8. Optical microscopy image of defective cell in $P V-1$, after the ageing process (106 thermal cycles), showing brown EVA discolorations.

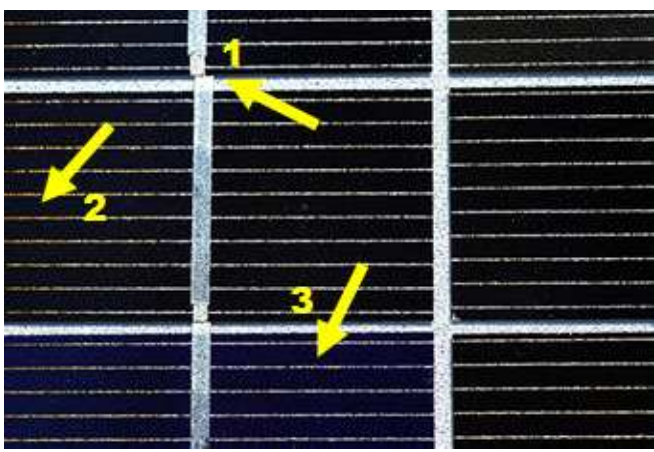

Fig. 9. Optical microscopy image of defective cells in $P V-1$, after the ageing process (106 thermal cycles), showing: 1 . distorted busbars 2. brown EVA discolorations and 3. cyan coating discolorations

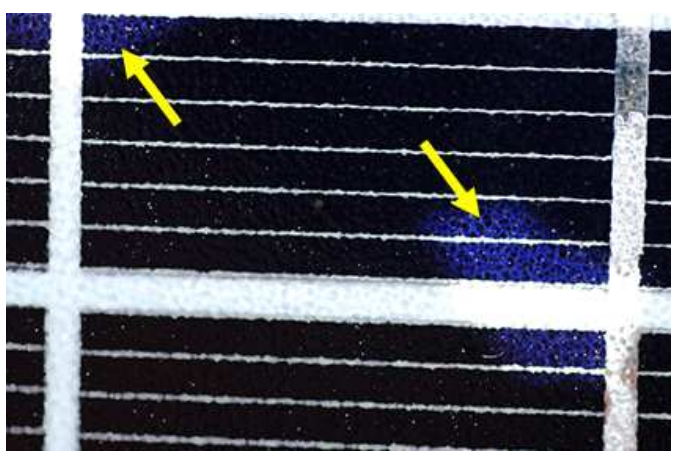

Fig. 10. Optical microscopy image of defective cells in $P V-3$, after the ageing process (106 thermal cycles), showing cyan coating discolorations.

\section{Concluding remarks and future work}

The presented study provided an assessment of the performance degradation and defect propagation mechanisms with regard to three mc-Si PV modules, by means of IR thermography, I-V measurements and optical microscopy imaging, through a thermal cycle accelerated ageing test.

It can be concluded that the results of the I-V measurements, upon the investigation of the efficiency degradation of each module, appear to be much more indicative of the thermal cycles ageing impact, than the resultant thermal signatures from the IR measurements. On the other hand, however, IR thermography diagnosis features the significant detection ability, providing valuable information with regard to the exact location of each defective cell and any possible propagation of the defective areas (as for the case of $P V-3$, after 106 thermal cycles). Moreover, the optical microscopy images successfully verified the presence of the diagnosed defects and efficiency degradation, in the form of certain discoloured brown-coloured EVA parts, distorted busbars and possibly degraded cyan-coloured anti-reflection coating of the silicon cell matrix.

Main limitation and, thus, disadvantage of such investigations is the inevitable lack of knowledge with regard to how these accelerated tests relate to field environments, in order to correlate each accelerated ageing process with actual lifetime (in years) in the field.

Further ambitions of the current research team, towards accelerated ageing testing and diagnostics/prognostics of PV modules are to:

- Enrich the accelerated ageing process scenario of the presented study with damp-heat, humidity-freeze and/or mechanical stress ageing tests.

- Investigate the application of DC voltage and continuous thermal imaging inspection to each tested module, during an ageing process.

- Apply current accelerated ageing tests to different technologies of PV modules. 


\section{References}

[1] J.A. Tsanakas, and P.N. Botsaris, "Passive and Active Thermographic Assessment as a Tool for Conditionbased Performance Monitoring of Photovoltaic Modules”, J. Sol. Energy. Eng., 133(2), 021012, 2011.

[2] J. Wohlgemuth, "IEC-61215: What it is and isn't", NREL PV Module Reliability Workshop, Golden, Colorado, U.S.A., 2012.

[3] W. Dallas, O. Polupan, and S. Ostapenko, "Resonance Ultrasonic Vibrations for Crack Detection in Photovoltaic Silicon Wafers", Meas. Sci. Technol., 18, 2007.

[4] A. Krenzinger, and A.C. de Andrade, "Accurate Outdoor Glass Thermographic Thermometry Applied to Solar Energy Devices”, Sol. Energy, 81, 2007.

[5] O. Breitenstein, J.P. Rakotoniaina, M. Kaes, S. Seren, T. Pernau, G. Hahn, W. Warta, and J. Isenberg, "Lock-in Thermography - A Universal Tool for Local Analysis of Solar Cells", Proc. 20th European Photovoltaic Solar Energy Conference and Exhibition (EUPVSEC), Barcelona, Spain, 2005.

[6] N.J.C.M. Van der Borg, and A.R. Burgers, "Thermography: Quality Control for Module Manufacturing", Proc. 3rd World Conference on Photovoltaic Energy Conversion, Osaka, Japan, 2003.

[7] R. Gupta, and O. Breitenstein, "Unsteady-state Lockin Thermography - Application to Shunts in Solar Cells", QIRT J., 4(1), 2007.

[8] M. Kasemann, M.C. Schubert, M. The, M. Kober, M. Hermle, and W. Warta, "Comparison of Luminescence Imaging and Illuminated Lock-in Thermography on Silicon Solar Cells”, Appl. Phys. Lett., 89, 224102, 2006. [9] T. Fuyuky, H. Kondo, T. Yamazaki, Y. Takahaschi, and Y. Uraoka, "Photographic Surveying of Minority Carrier Diffusion Length in Polycrystalline Silicon Solar Cells by Electroluminescence", Appl. Phys. Lett., 86, 262108, 2005.

[10] P. Sanchez-Friera, M. Piliougine, J. Pelaez, J. Carretero, and M. S. de Cardona, "Analysis of Degradation Mechanisms of Crystalline Silicon PV Modules After 12 Years of Operation in Southern Europe", Prog. Photovolt: Res. Appl., 19, 2011.
[11] K.R. McIntosh, N.E. Powell, A.W. Norris, J.N. Cotsell, and B.M. Ketola, "The Effect of Damp-Heat and UV Aging Tests on the Optical Properties of Silicone and EVA Encapsulants", Prog. Photovolt: Res. Appl., 19, 2011.

[12] P. Hacke, K. Terwilliger, S. Glick, D. Trudell, N. Bosco, S. Johnston, and S. Kurtz, "Test-to-Failure of Crystalline Silicon Modules", Proc. 35th IEEE Photovoltaic Specialists Conference, Honolulu (Hawaii), U.S.A., 2010.

[13] P. Hacke, M. Kempe, K. Terwilliger, S. Glick, N. Call, S. Johnston, and S. Kurtz, "Characterization of Multicrystalline Silicon Modules with System Bias Voltage Applied in Damp Heat", Proc. 25th European Photovoltaic Solar Energy Conference and Exhibition, Valencia, Spain, 2010.

[14] J.K. Mathew, J. Kuitche, and G. TamizhMani, “Test-to-Failure of PV Modules: Hotspot Testing”, Proc. 35th IEEE Photovoltaic Specialists Conference, Honolulu (Hawaii), U.S.A., 2010.

[15] J.H. Wohlgemuth, and S. Kurtz, "Using Accelerated Testing to Predict Module Reliability", Proc. 37th IEEE Photovoltaic Specialists Conference, Seattle, U.S.A., 2011.

[16] S. Kumar, and G. Kumar, "Analysis of Effect of Thermal Cycling Test on Photovoltaic Module Using EL Technique”, Inter. J. Adv. Eng. Res., 3(5), 2012.

[17] C.E. Packard, "The Challenge to Move from 'One Size Fits All' to PV Modules the Customer Needs", Proc. 26th European Photovoltaic Solar Energy Conference and Exhibition (EUPVSEC), Hamburg, Germany, 2011.

[18] E. Skoplaki, and J.A. Palyvos, "On the Temperature Dependence of Photovoltaic Module Electrical Performance: A review of Efficiency/Power Correlations", Sol. Energy, 83(5), 2009.

[19] A. Luque, and S. Hegedus, "Handbook of Photovoltaic Science and Engineering", WileyInterscience, Chichester, United Kingdom, 2003.

[20] M.A. Green, "Solar Cell Fill Factors: General Graph and Empirical Expressions", Solid-State Electron., 24, 1981. 